\title{
Sistem informasi multimedia untuk meningkatan UMKM pada Kota Pagar alam berbasis web
}

\author{
Iskandar, Yogi Isro' Mukti* \\ Podi Teknik Informatika, Sekolah Tinggi Teknologi Pagar Alam
}

Email Korespondensi : "Yogie.Isro.mukti@sttpagaralam.ac.id

\begin{abstract}
Pagar Alam in gething the data of improvement of UMKM then use manual system, process of collecting data of number UMKM, kind of UMKM so that of collecting data, reporting data non effective note taking of total UMKM and UMKM activities ar activity routinely done by goverment in getting UMKM data consist of total of UMKM, kinds of industry system developing method which used is Web Engenering method with some steps: Costumers, Comunication, Planning, Modelling, Construction and development. By desingning this system information, get information system, dinamiclay and updating hopely. Beside that this system information can be us one of alternativ media and conveying information with faster for user commonly.
\end{abstract}

Keywords : Website, Engering, Multimedia, UMKM

\section{Pendahuluan}

Perkembangan di era globalisasi sangat bergantung pada sektor ekonomi sebagai ukuran keberhasilan yang dilakukan oleh pemerintah. Peran masyarakat dalam pembangunan nasional, khususnya dalam pembangunan ekonomi, adalah Usaha Mikro, Kecil dan Menengah (UMKM). Posisi UMKM dalam perekonomian nasional memiliki peran penting dan strategis. Kondisi ini sangat dimungkinkan karena keberadaan UMKM cukup dominan dalam perekonomian Indonesia. [1]

Usaha Mikro Kecil dan Menengah (UMKM) saat ini mengalami perkembangan yang sangat pesat dari waktu kewaktu. Usaha Mikro Kecil dan Menengah (UMKM) merupakan sebuah terobosan baru dalam meningkatkan kesejahteraan bagi masyarakat. dengan adanya Usaha Mikro Kecil dan Menengah (UMKM) dapat membantu menopang perekonomian yang ada di Indonesia, karena menambah hasil perekonomian masyarakat. Masyarakat dituntut untuk menjadi mandiri dengan menciptakan sebuah usaha yaitu Usaha Mikro Kecil dan Menengah dan diharapkan dapat mengurangi angka pengangguran yang ada di Indonesia. Melihat keadaan lapangan pekerjaan saat ini yang setiap tahunya berkurang di Indonesia, sesuai dengan fakta yang ada pencari kerja lebih banyak dari ada yang menyediakan lapangan pekerjaan, sehingga Usaha Mikro Kecil dan Menengah dapat menjadi solusi bagi masyarakat untuk memperoleh penghasilan tanpa harus mencari pekerjaan.

Dalam usaha meningkatkan produktifitas dan efisiensi dari UMKM maka dapat memanfaatkan Teknologi Informasi dan Komunikasi (TIK ) secara efektif memberikan pengaruh langsung kepada UMKM. Pengaruh positif pada UMKM dapat menikmati berbagai keuntungan dari penggunaan TIK. Dimana UMKM dapat melakukan komunikasi secara cepat, meningkatkan produktifitas, membangun peluang bisnis baru, dan mereka juga dapat terhubung ke jaringan global dengan jangkauan secara internasional. 
Implementasi dari TIK bisa dilakukan dengan menggunakan websites dan e-mail untuk meningkatkan kualitas layanan dan memperbanyak jaringan pelanggan [2].

Dari penelitian yang dilakukan oleh Nency Extise Putri, dkk [3]. Dengan berjudul Aplikasi Berbasis Mult imedia Untuk Pembelajaran Hardware Komputer. Aplikasi interaktif untuk pengenalan spesifikasi perangkat keras komputer dibangun dengan menggunakan Macromedia Flash 8. Dimana dengan aplikasi ini akan lebih mudah mengenali bentuk dan fungsinya masing-masing Hardware komputer. Aplikasi ini berisi unsur multimedia seperti peta, gambar, teks, dan juga suara yang dibuat secara interaktif danmah untuk digunakan. Penelitian yang dilakukan Yeni Pariatin dan Yuda Zuliansa Ashari [4], tentang Perancangan Media Pembelajaran Interaktif Mata Pelajaran PKN untuk Penyandang Tunarungu Berbasis Multimedia (Studi Kasus di Kelas VII SMPLB Negeri Garut Kota). Penelitian ini merancang sebuah perangkat lunak media pembelajaran interaktif berbasismult imedia sebagai alat bantu guru dalam penyampaian isi materi PKN untuk kelas VII di SLB Negeri Garut Kota. Metode yang digunakan pada perancangan perangkat lunak ini menggunakan metode pengembangan multimedia menurut Luther (1994) yang dilakukan dalam 6 tahap. Perangkat lunak ini dibuat dengan menggunakan Tools Adobe Flash CS 3, Adobe Photoshop, Adobe Audition, Adobe after Effect, CorelDraw, dan Adobe Premiere. Dalam penelitian Chrisna Atmadji dan M. Arief Soeleman [5], mengenai Multimedia Pembelajaran Mata Kuliah Sistem Informasi Manajemen. Media yang dibuat dimaksudkan agar subjek lebih menarik, memotivasi siswa, dan mengaktifkan kelima indera. Untuk memenuhi kriteria ini, media harus dibuat dalam program animasi yaitu teknik dan proses konstruksi gerakan untuk benda tidak bergerak. Berdasarkan uji coba dengan multimedia. Secara teknis, hasilnya adalah siswa jauh lebih baik dalam belajar dan bisa memotivasi siswa untuk belajar lebih antusias

Berdasarkan hasil dari studi pendahuluan melalui observasi dan wawancara pada Dinas Prindustrian, Perdagangan, Koperasi dan UKM Kota Pagar Alam [6] khusunya pada bidang Koperasi dan UKM dan beberapa pelaku Usaha Mikro Kecil dan Menengah, sesuai dengan data tahun 2019 pada Disprindakop dan UKM, terdaftar 2024 Usaha Mikro Kecil dan Menengah (UMKM) di Kota Pagar Alam yang merupakan gabungan dari usaha industri, usaha perdagangan, usaha jasa, usaha pertanian dan usaha kerajinan. Tingkat penghasilan seorang pelaku UMKM juga tergantung musim sepert i tahun baru, lebaran dan lainya, Biasanya pada hari-hari tersebut meningkat karena seorang pembeli kebanyakan visitor dari luar Kota Pagar Alam. Hal ini tentu saja membuat pelaku Usaha Mikro Kecil dan Menengah (UMKM) kebingungan untuk meningkatkan penghasilan selain dengan menunggu pembeli datang kelokasi.

Oleh karena itu, peneliti bermaksud membuat sistem informasi multimedia untuk meningkatkan UMKM pada kota Pagar Alam yang memudahkan banyak pihak baik di tingkat perdesaan, kelurahan maupun mitra desa/sponsor dapat berinteraksi dalam pembangunan desa. Warga desa yang satu juga dapat belajar mengenai keberhasilan kegiatan wirausaha desa yang lain, saling bertukar informasi dan ilmu wirausaha, desa juga dapat menonjolkan kegiatan-kegiatan wirausaha desa secara up to date. Desa dapat melakukan pengolahan data untuk desanya dan sekaligus dapat menyebarluaskan hasil-hasil wirausaha, melakukan promosi, dan bahkan dapat melakukan penawaran kepada mitra desa/sponsor lainnya yang mau dan berminat menjalin kerjasama dengan desa bahkan dapat melakukan transaksi untuk penjualan hasil-hasil wirausaha.

Pembuatan sistem informasi multimedia untuk meningkatkan UMKM pada kota Pagar Alam ini tujuannya yang terpentingnya adalah memberikan kemudahan dalam belajar berwirausaha dan memang ditujukan untuk warga desa yang awam dengan menonjolkan multimedia pembelajaran wirausaha yang interaktif. Dalam jangka panjang sistem informasi multimedia untuk meningkatkan UMKM pada kota Pagar Alam akan dapat memberikankemanfaatan pada terbentuknya kemandirian warga desa dan mendukung pelaksanaan otonomi desa dalam kegiatan-kegiatan wirausaha/bisnis yang tentu saja akan mensejahterakan desa tersebut. 


\section{Metode Penelitian}

Penelitian ini menggunakan metode pengembangan sistem RAD (Rapid Aplication Development) [7], mulai dari tahap requirements planning, yaitu dengan melakukan pengumpulan data, analisis kebutuhan baik perangkat lunak maupun perangkat keras yang dibutuhkan sesuai dengan objek penelitian pada UMKM di Kota Pagar Alam, selanjutnya masuk pada tahap desain/perancangan mulai dari kebutuhan hubungan antara pengguna dengan sistem, kemudian sistem dengan sistem, dalam hal ini menggunakan UML (Unified Modeling Language), mulai dari use case diagram, activity diagram, squency diagram, dan class diagaram, kemudian dilakukan analisis terhadap desain/rancangan kepada ahli bidang desain dan rancangan, yang selanjutnya jika sudah valid, selanjutnya dilakukan pembuatan sistem Informasi [8] Multimedia UMKM, pada tahap ini juga dilakukan analisis dan pengujian terhadap sistem yang dibangun, dan jika sudah dinyatakan valid oleh ahli maka selanjutnya masuk pada tahap implementasi sistem [9], yaitu dengan mengimplemntasikan sistem kepada pelaku UMKM yang ada di Kota Pagar Alam.

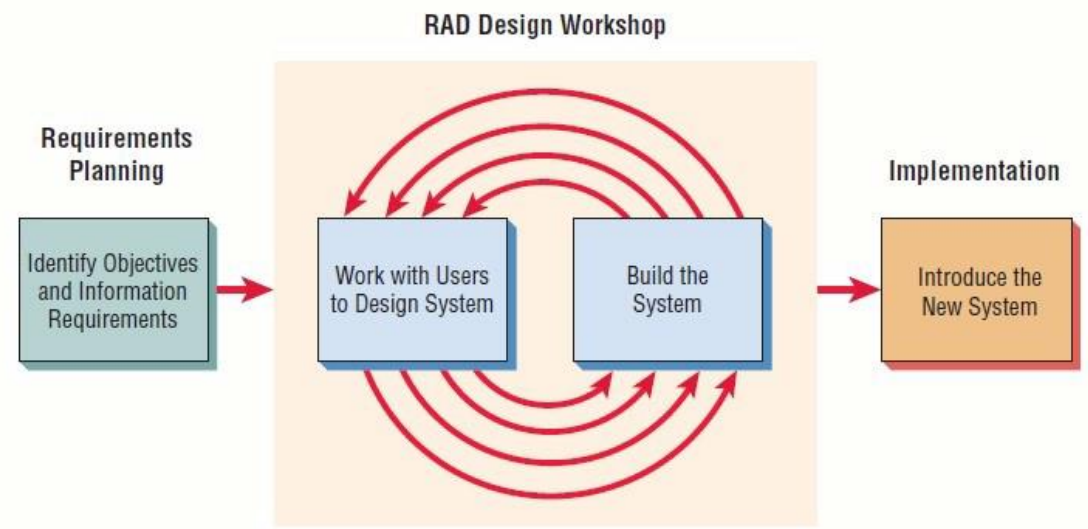

Gambar 1. Rapid Aplication Development (RAD) Sumber : kendall 2010 [7]

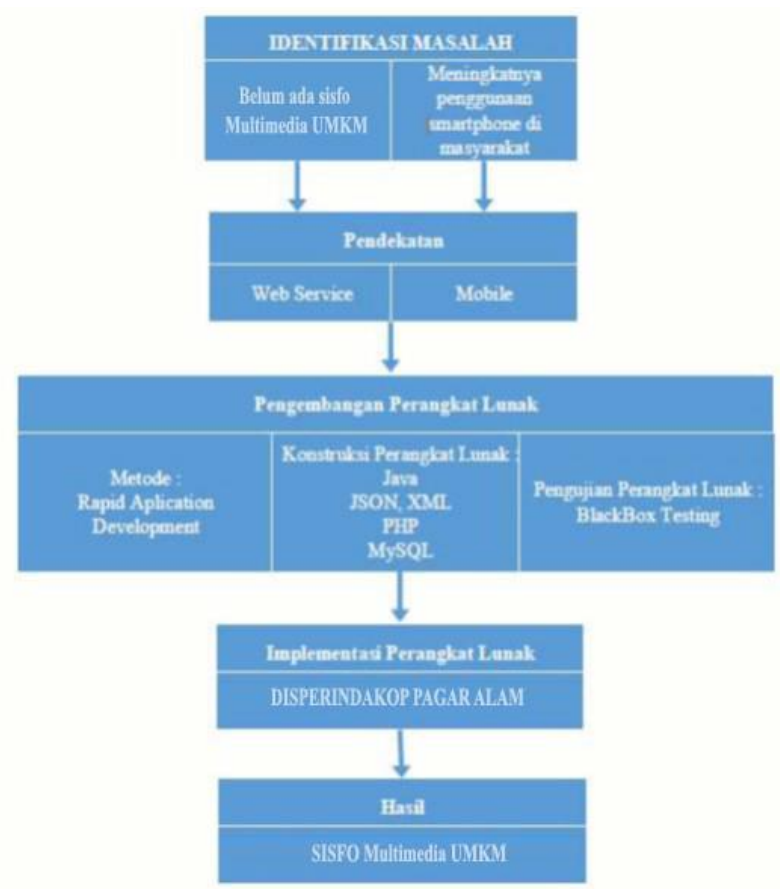

Gambar 2. Kerangka Pemikiran 
Agar penelitian ini berjalan sesuai dengan harapan, maka dibuat kerangka pemikiran yang sesuai dengan bahasan, yang menggambarkan rangkaian proses pembuatan Sistem Informasi Multimedia UMKM Pada Kota Pagar Alam seperti pada gambar 2.

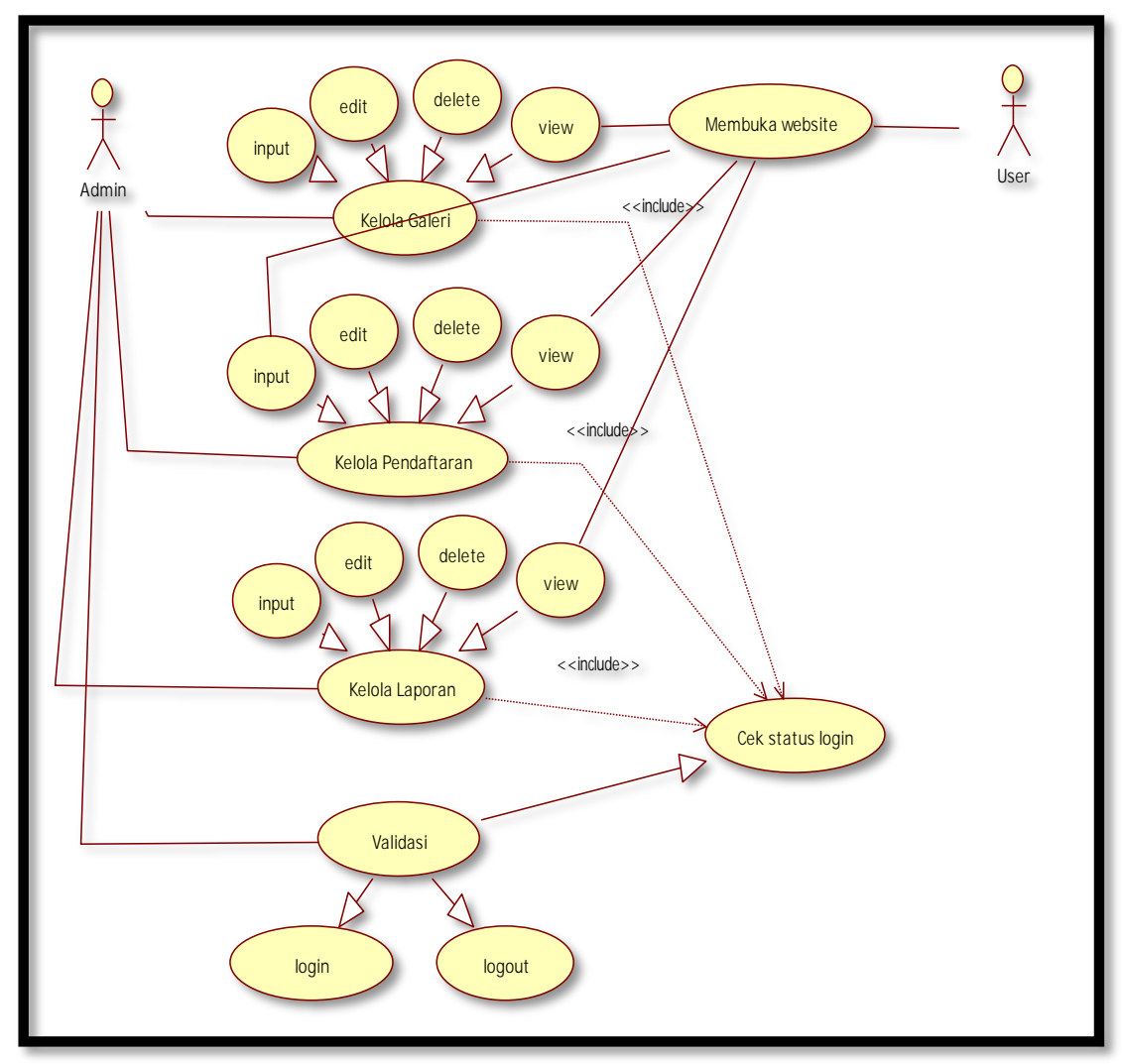

Gambar 3. Use case Diagram

Selanjutnya dalam mengimplementasikan proses yang terjadi dibuatlah use case diagram yang menggambarkan antara hubungan user dengan sistem, maupun hubungan antara sistem ke sistem, seperti pada gambar 3 .

Proses selanjutnya dilakukan dengan pembuatan activity diagram untuk memperjelas proses sistem yang dibuat, seperti hubungan proses antara admin dengan sistem, seperti admin melakukan akses kepada sistem, selanjutnya sistem akan menampilkan form login, kemudian admin memasukan username dan password dan selanjutnya sistem akan memproses apakah data yang dimasukan valid atau tidak dan seterusnya sampai proses selesai seperti yang ditampilkan pada gambar 4. 


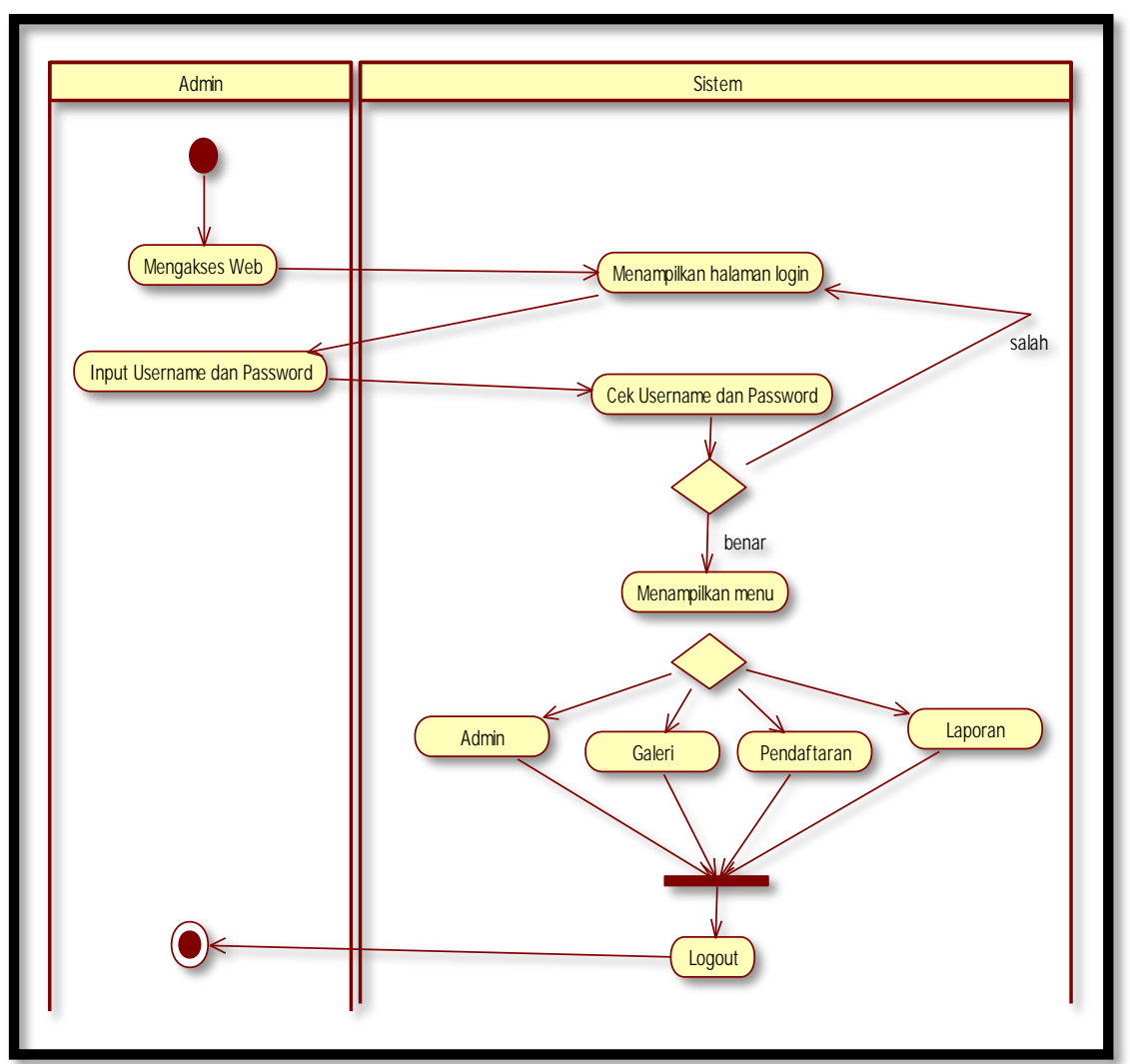

Gambar 4. Acitivity Diagram

Proses selanjutnya adalah pembuatan squence diagram, untuk menggambarkan proses lebih dalam lagi hal ini dilakukan agar sistem yang dibuat, sesuai dengan standar arsitektur perangkat lunak, seperti yang ditampilkan pada gambar 5.

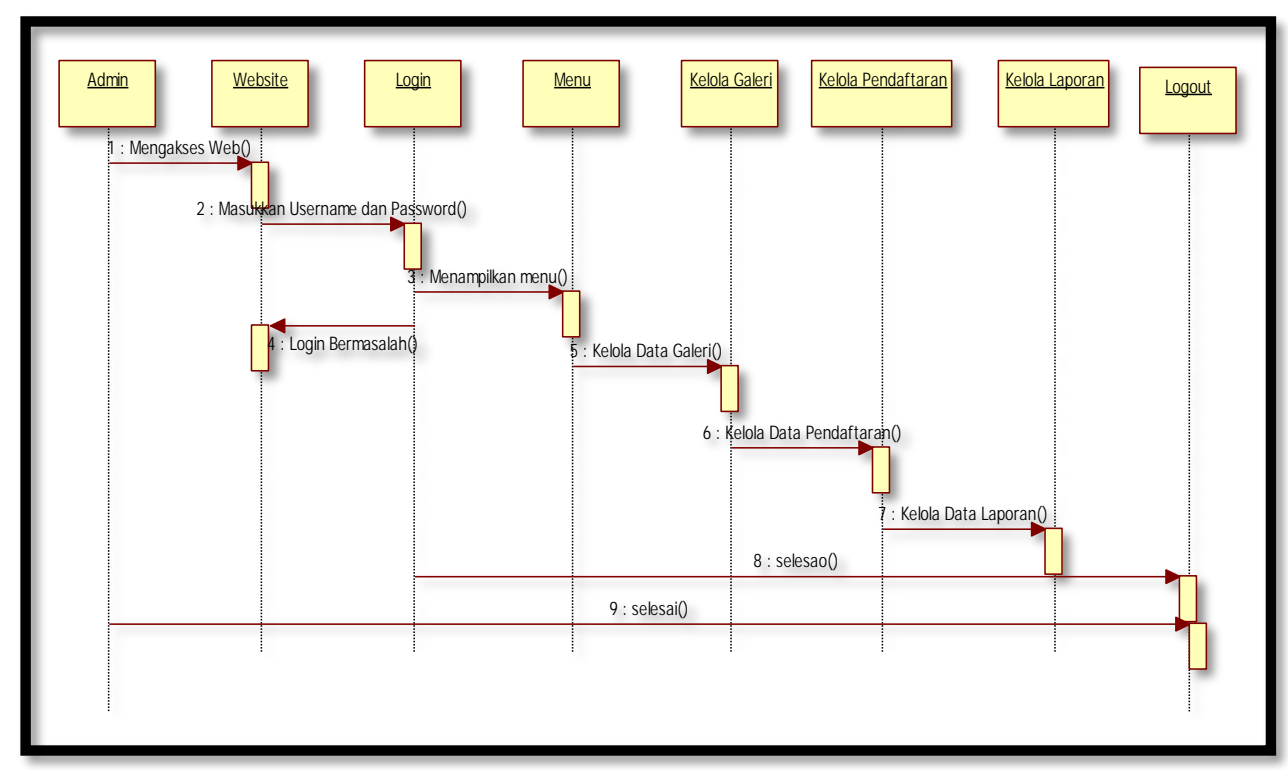

Gambar 5, Sequence Diagram 
Tahap selanjutnya adalah melakukan perancangan class diagram, hal ini untuk memudahkan dalam merancang dan mengimplementasikan sistem yang dibuat dengan basis data yang digunakan, agar tidak terjadi kesalahan dalam mengimplementasikan basis data. Seperti yang nampak pada gambar 6.

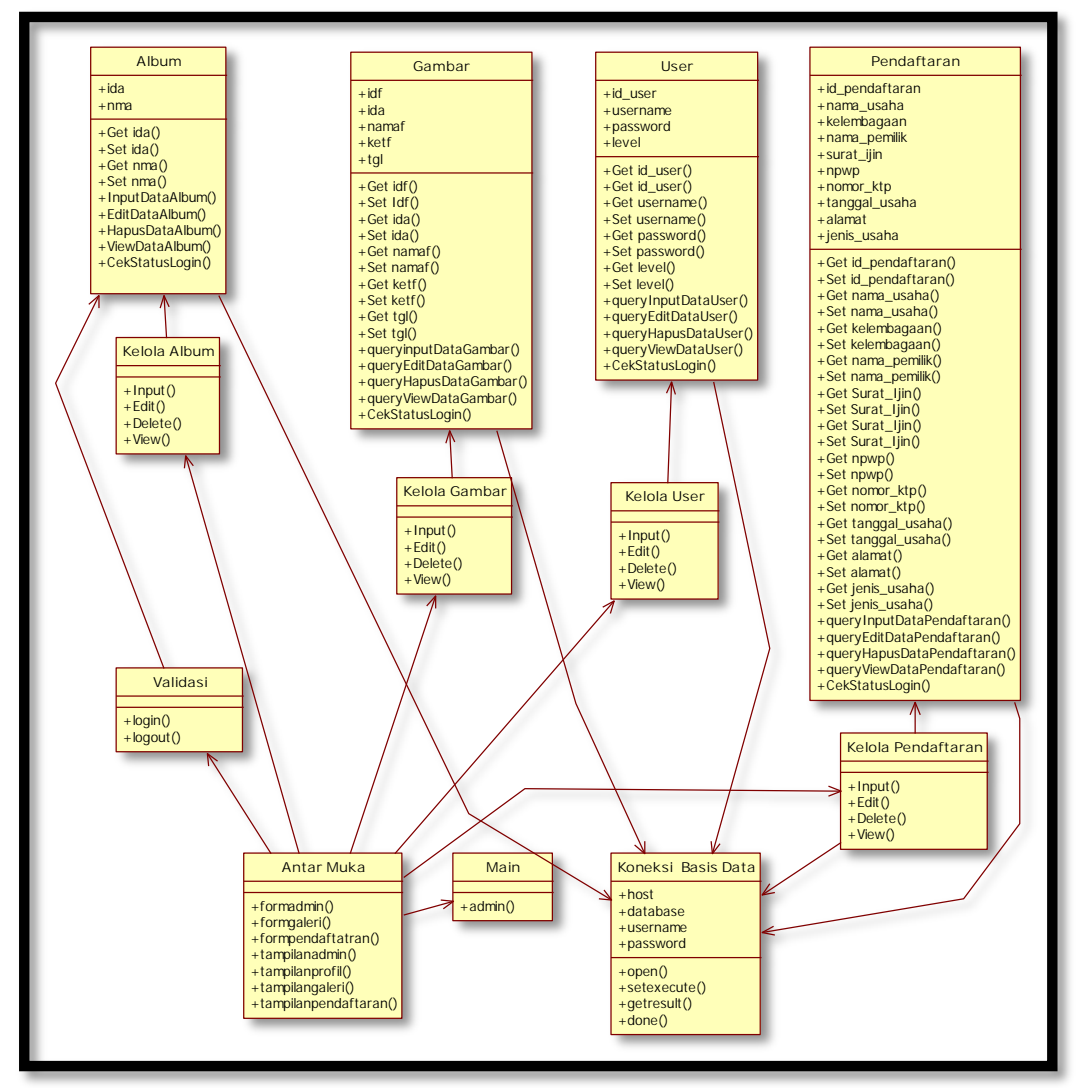

Gambar 6. Class Diagram

\section{Hasil dan Pembahasan}

Pengujian yang dilakukan dengan menggunakan komputer dengan spesifikasi AMD Ryzen 5, RAM 8 GB, Sistem Operasi Windows 1064 bit. Dengan software Katalon Studio didapatkan hasil yang valid terhadap Sistem Informasi Multimedia UMKM berbasis web. Seprti pada gambar 7.

Hasil pengujian pada ahli didapatkan dijadikan acuan untuk merevisi produk sehingga menghasilkan produk yang valid. Desain produk dinilai oleh para ahli pada saat produk sudah jadi. Skor yang diperoleh dari para ahli tersebut dicari rata-ratanya dengan menggunakan rumus :

$$
\begin{aligned}
& \mathrm{R}=\frac{\sum_{i=1}^{n} V i}{n} \quad \\
& \text { Keterangan: } \\
& \mathrm{R} \quad=\text { Nilai rata-rata hasil penilaian validator } \\
& \mathrm{Vi} \quad=\text { Skor hasil penilaian Validator ke-i } \\
& \mathrm{N} \quad=\text { Banyaknya data }
\end{aligned}
$$




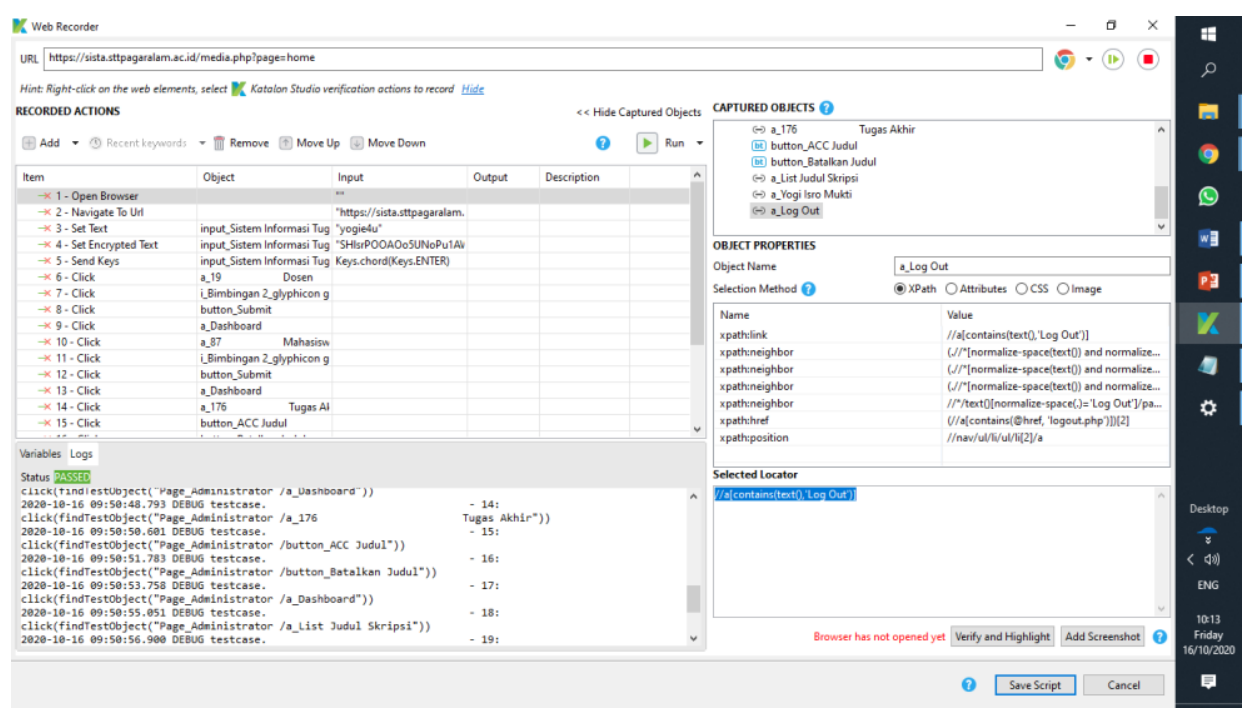

Gambar 7. Pengujian Sistem

Hasil analisis tersebut di interprestasikan dengan menggunakan kategori Valid dengan skor 3,5 dengan mengacu pada tabel 1.

Tabel 1. Kategori Skor ahli

\begin{tabular}{ll}
\hline Skor & Kategori \\
\hline $4,1-5$ & Sangat Valid \\
\hline $3,1-4$ & Valid \\
\hline $2,1-3$ & Cukup Valid \\
\hline $1,1-2$ & Kurang Valid \\
\hline $0-1$ & Sangat Tidak Valid \\
\hline
\end{tabular}

Untuk menguji apakah aplikasi yang sudah di rancang oleh peneliti tersebut mempunyai efektifitas atau tidak terhadap UMKM maka kita hitung dengan rumus N-gain untuk melihat Efektifitas :

$\mathrm{g}=\frac{S_{\text {Post }}-S_{\text {Pre }}}{S_{\text {Maks }}-S_{\text {Pre }}}$

Keterangan:

Spost $=$ Skor Postest

Spre $=$ Skor Pretest

Smaks $=$ Skor Maksimal

Kemudian hasil perhitungan $\mathrm{N}$-gain di interpretasikan pada table 2.

Tabel 2 . Tabel Kriteria N-gain

\begin{tabular}{ll}
\hline Besarnya & Interpretasi \\
\hline $\mathrm{g}>0,7$ & Tinggi \\
$0,3 \leq \mathrm{g} \geq 0,7$ & Sedang \\
$\mathrm{g}<0,3$ & Rendah \\
\hline
\end{tabular}

Dengan mengacu pada tabel 2. Didapatkan N-gain sebesar 0,8, sehingga dinterprestasikan Tinggi. Setelah semua proses analisis data telah selesai dilakukan maka kriteria keberhasilan dari penelitian ini adalah akan menghasilkan Sistem Informasi Multimedia untuk meningkatkan UMKM di Kota Pagar Alam. 
Dengan adanya Sistem Informasi dapat mempermudah pelaku Usaha Mikro Kecil Menengah mendaftarkan usaha milik mereka sehingga tidak perlu lagi datang ke Dinas Perindagkop dan UKM Kota Pagar Alam untuk mendaftarkan Usaha mereka karena website dapat diakses dimana saja dan kapan saja.

Gambar 8 merupakan hasil output dari sistem yang dibangun yang bisa diaskes oleh pelaku UMKM di Kota Pagar Alam, dan berdasarkan nilai N-gain sebesar 0,8, hal ini mengindikasikan bahawa sistem yang dibangun benar-benar dapat memajukan UMKM di Kota Pagar Alam.

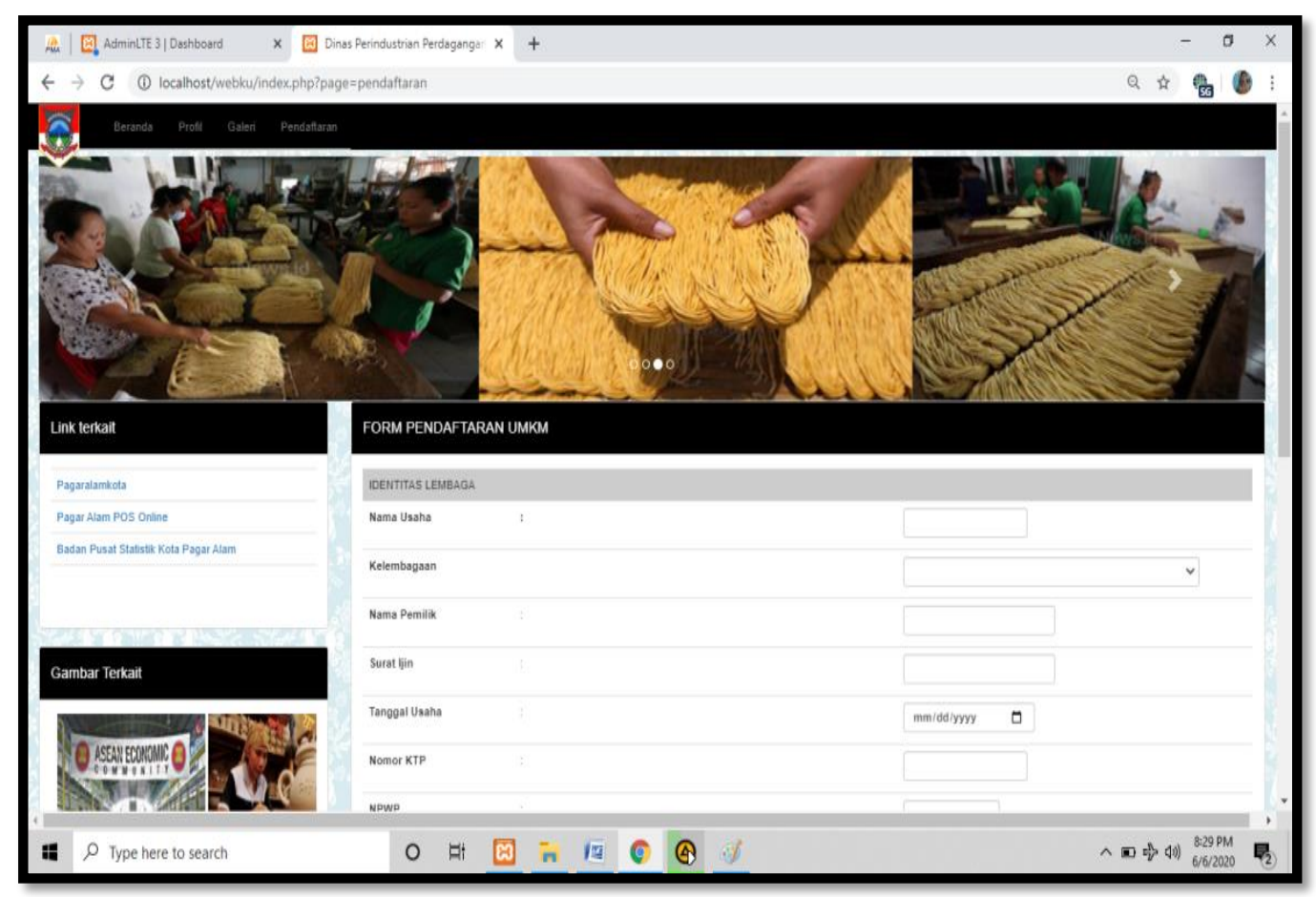

Gambar 8. Halaman Utama Sistem Informasi UMKM

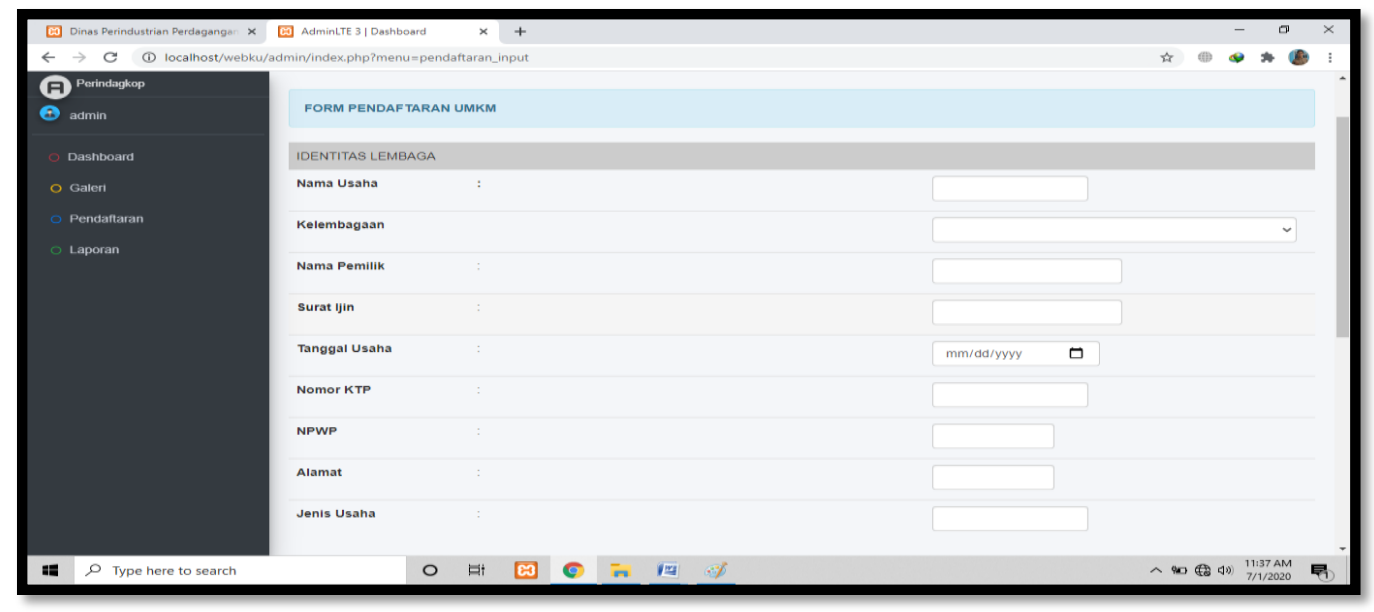

Gambar 9. Dasboard Kontrol Administrator 
Untuk bagian konfigurasi dari Sistem Informasi ini dibuatkan bagian kontrol untuk memudahkan pengaturan sistem, baik input, proses maupun output seperti yang tampak pada gambar 9 .

\section{Kesimpulan}

1. Sistem yang dibangun berjalan sesuai dengan yang diharapkan, yakni memberikan Kemudahan bagi pelaku Usaha Mikro Kecil Menengah mendaftarkan usaha milik mereka sehingga tidak perlu lagi datang ke Dinas Perindagkop dan UKM Kota Pagar Alam.

2. Sistem yang dibangun menggunakan metode RAD, dengan menggunakan bahasa pemrograman PHP, dengan basis data MySQLi [1], dan selanjutnya perlu dilakukan perluasan agar sistem Informasi Multimedia Untuk Meningkatkan UMKM Pada Kota Pagaralam Berbasis WEB, bisa digunakan secara maksimal

\section{Ucapan Terimakasih}

Dalam penelitian ini tidak lepas dari bantuan berbagai pihak terutama kepada Sekolah Tinggi Teknologi Pagar Alam (STTP), yang memberikan dukungan mulai dari proses proposal hingga penelitian ini selesai, selanjutnya peneliti menghaturkan terima kasih kepada Dinas Perindustrian Perdagangan Koperasi dan UKM Kota Pagar Alam yang telah mengizinkan dilakukannya penelitian terkati kegiatan pendataan UMKM. Peneliti juga mengucapkan kepada kemenristek dikti yang telah membiayai penelitian ini, sehingga penelitian yang dilakukan bisa berjalan sesuai dengan yang diharapkan.

\section{Daftar Pustaka:}

[1] S. N. Sarfiah, H. E. Atmaja, and D. M. Verawati, "Umkm Sebagai Pilar Membangun Ekonomi Bangsa Msmes the Pillar for Economy," J. REP (Riset Ekon. Pembangunan), vol. 4, no. 2, pp. 137-146, 2019.

[2] A. Basry and E. M. Sari, "Penggunaan Teknologi Informasi dan Komunikasi (TIK) pada Usaha Mikro, Kecil dan Menengah (UMKM)," IKRA-ITH Inform. J. Komput. dan Inform., vol. 2, no. 3, pp. 53-60, 2018.

[3] W. Roselina, "Aplikasi Berbasis Multimedia Untuk Pembelajaran Hardware Komputer," J. Edik Inform., vol. 1, no. Pembelajaran Hardware Komputer, pp. 70-81, 2015.

[4] D. P. Yaw, "Perancangan Media Pembelajaran Interaktif Mata Pelajaran PKN Untuk Penyandang Tunarungu Berbasis Multimedia (Studi kasus di Kelas VII SMPLB Negeri Garut Kota)," J. STTGarut, vol. 9, no. 1, pp. 76-99, 2010.

[5] R. SINEN, Penerapan Sistem Informasi Manajemen Pendidikan Dalam Proses Pembelajaran Di SMP Negeri 21 Makassar, vol. 2, no. 2. 2017.

[6] Kominfo, "Geografi Pagar Alam.” Dinas Kominfo Pagar Alam, Pagar Alam, 2015.

[7] K. E. Kendall and J. E. Kendall, Systems Analysis And Design Edition 8. 2010.

[8] H. Saragih and Harisno, Renncana Strategis Teknologi Informasi (IT) dan Sistem Informasi (IS) Pada Proses Bisnis Perusahaan, 1st ed. Yogyakarga: Graha Ilmu, 2014.

[9] J. Ward and J. Peppard, Strategic Planning for Information Systems. England, 2002.

[10] Sugiyono, Metode penelitian pendidikan: (pendekatan kuantitatif, kualitatif dan $R \& D$ ). Bandung: Alfabeta, 2008. 
